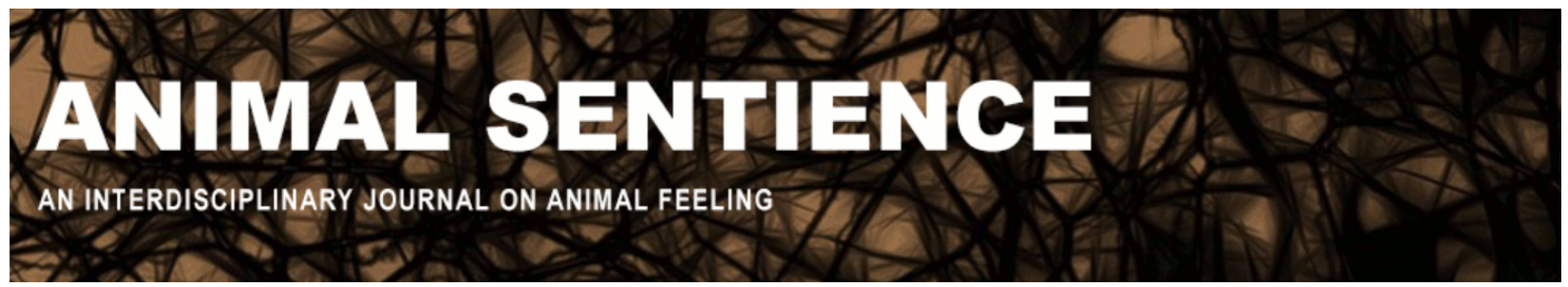

Dowe, David L. and Chmait, Nader (2020) Game theory and Artificial Intelligence in just preservation. Animal Sentience 27(22)

DOI: $10.51291 / 2377-7478.1555$

Date of submission: 2020-02-12

Date of acceptance: $2020-02-20$

(c)

This article has appeared in the journal Animal

Sentience, a peer-reviewed journal on animal

cognition and feeling. It has been made open access,

free for all, by WellBeing International and deposited

in the WBI Studies Repository. For more information,

please contact

wbisr-info@wellbeingintl.org.

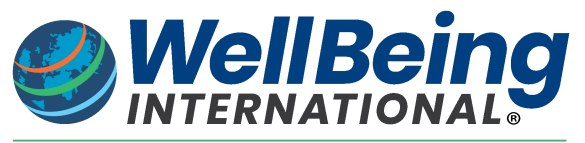

SOLUTIONS FOR PEOPLE, ANIMALS AND ENVIRONMENT 


\title{
Game theory and Artificial Intelligence in just preservation
}

Commentary on Treves et al. on Just Preservation

\author{
David L. Dowe \\ Faculty of Information Technology, Monash University \\ Nader Chmait \\ Faculty of Information Technology, Monash University
}

\begin{abstract}
We humans can show presumption, arrogance and many dubious traits. By virtue of being land-dwelling, dexterous, relatively intelligent, and having good communication hardware and (good) fortune, we have for recent millennia largely had dominion of our planet. Yet humans often do not treat themselves (let alone other species) particularly well. Treves et al.'s idea of a multispecies justice system - not "prioritizing humans" but "finding practical ways to work within human systems" - invites consideration.
\end{abstract}

David L. Dowe works on machine learning, statistics and data science - including the Bayesian information-theoretic Minimum Message Length (MML) principle - and applications, including intelligence. He welcomes Al for social good but is concerned about adverse impacts. Website

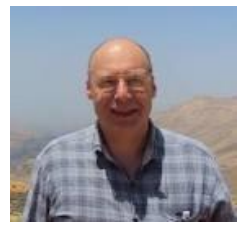

Nader Chmait is a researcher in Al and data science. His work is focused on intelligent agent systems, group decision-making, collective (artificial) intelligence, statistical modelling under uncertainty and artificial general intelligence. Website

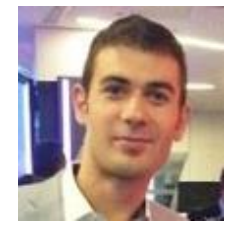

1. Leaving everything to the markets - and the prisoner's dilemma. Some schools of economics make the assumption that efficiency and optimal allocation of resources result when all agents act out of unbridled self-interest. We agree with Treves et al. (2019) about "[c]laims made about protecting the future by maximizing wealth today" and "short-term profiteering from nature veiled by claims about poverty alleviation or economic trickle-down". The prisoners' dilemma (Rapoport \& Chammah, 1965) and the tragedy of the commons (Hardin, 1968) provide simple counter-examples to market efficiency. Emissions and climate change (Treves et al., 2019; Alexander, 2019; Attfield, 2019; Baker, 2019; Bergstrom, 2019; Gray, 2019; Palmer \& Fischer, 2019; IPBES, 2019) show that binding agreements are needed in the justice system. Whether this need could be made more evident to the public by reporting changes in standard deviations rather than just in means and averages (of temperatures) - or even by inviting various commentators to enter prediction competitions - co-operation and agreements are surely necessary.

2. Intelligence and rights. Neuroscience presents evidence of cognition and emotional experience in animals including fish and bees (Correia Caeiro, 2020). Stories of intelligent non- 
human animals abound (Greenfield et al., 2011; Pilley \& Hinzmann, 2013; de Waal, 2016; Paxinos, 2015). Evidence of plant intelligence, too, is increasing (Attfield, 2019; Washington, 2019; Michmizos \& Chilioti, 2019). Whether or not humans are the most cognitively complex species (Batavia, 2020), can we be sure they are the most intelligent Earth-based life-form (Dowe \& Hernández-Orallo, 2011)?

3. Modelling optimal preservation efforts: A simple multi-objective criterion. Correia Caeiro (2020) emphasises the importance of protecting non-human species (even when human and nonhuman individuals are in conflict). For biological systems, just preservation efforts should not be purely anthropocentric (Chapman \& Huffman, 2017). We need to acknowledge the importance of diversity across the spectrum, and the equal opportunity to co-exist, for any species. One way to allocate preservation efforts could be by modelling:

i) An estimated value, $a>0$, to humans for preserving a species (cf. Batavia, 2020).

ii) An estimate of the extinction or contraction rate $b(t)$ of a species, varying with time, $t$ (Elith \& Leathwick, 2009). A contraction rate of $b(1)$ denotes that $1-b(1)$ of that species remains in period 2.

Preservation efforts could then be modelled as the product of $a$ and the $b(t)$ over the period of time (1 to $T$ ), or more formally:

$$
\text { PreservationEffort }=a b(1) \ldots b(T) \quad \text { (equation } 1)
$$

This agrees with Lambert (2019), who notes that the inadequate recognition of the needs of animal species is based on the high value accorded to protecting humans (focussing on $a$ ) relative to other species (focussing on $b$ ). Reducing just preservation efforts to the model in equation 1 would of course be an oversimplification, neglecting the problem of how to implement intraspecies versus inter-species preservation as well as human entitlement in allocating preservation efforts for different species.

4. Artificial Intelligence (Al) and just preservation. Preserving species "for their own sake" becomes particularly important as we consider rapid developments in Al - for example, robospecies (like virtual bees) that mimic and replicate the functionality of natural endangered species. Such approaches overlook ethical aspects of preservation (Gleadow, Hanan \& Dorin, 2019) and questions of impartiality. If used strategically, however, artificial (swarm) robots or robo-species could assist in reconstructing the desired environmental conditions for existing natural species to thrive again and evolve (Gleadow, Hanan \& Dorin, 2019).

Robo-species, unlike many natural ones, could be purpose-designed for social good, suppressing the rivalry in consumption inherent in the prisoner's dilemma. Intelligent robots (e.g., virtual bees as pollinators) could be used to transform and prepare currently uninhabitable environments in which their biological peers could then subsist and grow. Al might also have a positive role as the interacting factors (Palmer \& Fischer, 2019; Spiegel, 2020) and justice system (Treves et al., 2019) become increasingly complex. Amongst the downsides or even dangers of Al 
(Solomonoff, 1967; Dowe, 2014), its influence could be comparable to that of biological invasive species (IPBES, 2019; Washington, 2019).

Preservation and nature have themselves made positive contributions both to $\mathrm{Al}$ and to computing more generally. Nature-based computational search algorithms include ant colony optimisation, simulated annealing (Chmait \& Challita, 2013) and genetic algorithms (Bossomaier \& Green, 2000).

Acknowledgments: D.L.D. had initial discussions with David G. Green and Marc Cheong.

\section{References}

Alexander, S. M. (2019). Reconciling just preservation. Animal Sentience 27(6).

Attfield, R. (2019). Futurity, selves and further organisms. Animal Sentience 27(4).

Baker, L. (2019). To preserve or to conserve? Animal Sentience 27(7).

Batavia, C. (2020). Is anthropocentrism really the problem? Animal Sentience 27(20).

Bergstrom, B. J. (2019). Just reductionism: In defense of holistic conservation. Animal Sentience 27(8).

Bossomaier, T. R., \& Green, D. G. (2000). Complex Systems. Cambridge University Press.

Chapman, C. A., \& Huffman, M. A. (2018). Why do we want to think humans are different? Animal Sentience 23(1).

Chmait, N., \& Challita, K. (2013). Using simulated annealing and ant-colony optimization algorithms to solve the scheduling problem. Computer Science and Information Technology, 1(3), 208-224.

Correia Caeiro, C. (2020). Comparative cognition and nonhuman individuality. Animal Sentience 27(16).

de Waal, F. (2016). Are We Smart Enough to Know How Smart Animals Are? WW Norton \& Co.

Dowe, D. L. (2014). Is Stephen Hawking right? Could Al lead to the end of humankind?. The Conversation.

Dowe, D. L., \& Hernández-Orallo, J. (2011). Mammals, machines and mind games. Who's the smartest?. The Conversation.

Elith, J., \& Leathwick, J. R. (2009). Species distribution models: Ecological explanation and prediction across space and time. Annual Review of Ecology, Evolution, and Systematics, 40, 677-697.

Gleadow, R., Hanan, J., \& Dorin, A. (2019). Averting robo-bees: Why free-flying robotic bees are a bad idea. Emerging Topics in Life Sciences, 3(6), 723-729.

Gray, J. (2019). Granting political representation to non-humans. Animal Sentience 27(5). Hardin, G. (1968). The tragedy of the commons. Science, 162(3859), 1243-1248.

IPBES. (2019). Nature's dangerous decline 'unprecedented'; Species extinction rates 'accelerating'. Media release, Intergovernmental Science-Policy Platform on Biodiversity and Ecosystem Services.

Lambert, J. E. (2019). The intrinsic value of nature. Animal Sentience 27(13). 
Lyn, H., Greenfield, P. M., Savage-Rumbaugh, S., Gillespie-Lynch, K., \& Hopkins, W. D. (2011). Nonhuman primates do declare! A comparison of declarative symbol and gesture use in two children, two bonobos, and a chimpanzee. Language and Communication, 31, 63-74.

Michmizos, D., \& Chilioti, Z. (2019). A roadmap towards a functional paradigm for learning and memory in plants. Journal of Plant Physiology, 232(1), 209-215.

Palmer, C., \& Fischer, B. (2019). Just policy paralysis? Animal Sentience 27(3).

Paxinos, S. (2015). Scientific studies of animal intelligence and emotion reveal surprising traits. Sydney Morning Herald.

Pilley, J. W., \& Hinzmann, H. (2013). Chaser: Unlocking the Genius of the Dog Who Knows a Thousand Words. Houghton Mifflin Harcourt.

Rapoport, A., \& Chammah, A. M. (1965). Prisoner's Dilemma. University of Michigan Press.

Solomonoff, R. J. (1967). Inductive Inference Research Status Spring 1967. Rockford Research, Cambridge, MA.

Spiegel, R. (2019). Protecting patients who lack a voice. Animal Sentience 27(11).

Treves, A., Santiago-Ávila, F., \& Lynn, W. (2019). Just preservation. Animal Sentience 27(1).

Washington, H. (2019). Justice for nature. Animal Sentience 27(2). 


\section{Call for Papers}

Special Issue of the Journal of Consciousness Studies

Plant Sentience: Theoretical and Empirical Issues

Guest Editors: Vicente Raja (Rotman Institute of Philosophy, Western University) Miguel Segundo-Ortin (School of Liberal Arts, University of Wollongong)

In this special issue, we address the issue of plant sentience/consciousness from different disciplines that combine both theoretical and empirical perspectives. Some of the questions to be addressed in the special issue include the following:

- Plants exhibit interesting behaviors; does this entail that they are conscious to some extent?

- What are the requirements for a living organism to be conscious? Do plants meet these requirements?

- What does the possibility of plant sentience/consciousness entail for the study of the evolution of consciousness?

- Is it just a categorical mistake to attribute consciousness to plants?

- Can we talk about different levels or degrees of consciousness?

\section{How to submit?}

\section{Deadline: June 1st, 2020}

Please submit your papers (max. 9000 words including footnotes, references, abstract, etc.) to vgalian@uwo.ca with subject "Paper Special Issue JCS".

For more information, including bibliography and more detailed descriptions of the topics and questions to be addressed in the papers submitted to the special issue, please contact the guest editors atvgalian@uwo.ca (Vicente) or ms0693@uowmail.edu.au (Miguel). 